\title{
CONTRIBUIÇÕES DE PAULO FREIRE NO ENSINO DE MATEMÁTICA: ETNOMATEMÁTICA NA EDUCAÇÃO DE JOVENS E ADULTOS
}

DOI: $10.48075 /$ RI.V24I2.26534

Liliane Rodrigues de Almeida Menezes ${ }^{1}$

Elisangela Aparecida Pereira de Melo

RESUMO: Este artigo reflete sobre as contribuições de Paulo Freire no ensino de Matemática para a Educação de Jovens e Adultos (EJA), e tem como objetivo analisar os pressupostos freireanos nas práticas pedagógicas de professores que ensinam Matemática nessa modalidade de ensino. A metodologia utilizada foi a pesquisa bibliográfica que abordou pontos importantes sobre: Paulo Freire e sua importância para a Educação brasileira; Educação de Jovens e Adultos; Modalidade de ensino; O ensino da Matemática na EJA; Os pressupostos freireanos e a Educação Matemática no contexto da Educação de Jovens e Adultos, na perspectiva da Etnomatemática trazendo as metodologias mobilizadas para a difusão de conhecimentos nessa modalidade de ensino e a repercussão do processo de ensino e de aprendizagem articulados aos estudos da Etnomatemática. A pesquisa revelou que os pressupostos freireanos articulados aos estudos da Etnomatemática estão presentes quando o professor cria argumentos e faz levantamento de problemas socioculturais e educativos com os estudantes para trabalhar os conteúdos matemáticos. Assim, os estudos freireanos, os da Etnomatemática e da Educação Matemática apresentam interlocução na efetivação e organização do ensino de Matemática para a EJA, tendo a problematização e o diálogo como elementos propulsores na construção do ensino e da aprendizagem.

Palavras-chave: Método Paulo Freire; Educação Matemática; Educação de Jovens e Adultos e Etnomatemática Ensino e Aprendizagem.

\section{PAULO FREIRE'S CONTRIBUTIONS IN TEACHING MATHEMATICS: ETHNOMATEMATICS IN YOUTH AND ADULT EDUCATION}

ABSTRACT: This article reflects on the contributions of Paulo Freire in the teaching of Mathematics for the Education of Youth and Adults (EJA) and aims to analyze the Freirean assumptions in the pedagogical practices of teachers who teach Mathematics in this type of teaching. The methodology used was bibliographic research that addressed important points about: Paulo Freire and its

\footnotetext{
${ }^{1}$ Mestre em Educação pela Universidade Federal do Tocantins (UFT). E-mail: rodriguesliliane926@gmail.com

2 Doutora em Educação em Ciências e Matemáticas pela Universidade Federal do Pará. Professora efetiva da Universidade Federal do Tocantins - Campus de Araguaína. Líder do Grupo de Estudo e de Pesquisas em Sistemas Socioculturais de Educação Matemática (SisMat); Membra do Grupo de Estudos e Pesquisas de Práticas Investigativas em Educação Matemática (GEPIMat) e do Grupo de Estudos e Pesquisa em Ensino de Ciências e Matemática no Contexto da Amazônia Legal. E-mail: elisangelamelo@mail.uft.edu.br
} 
importance for Brazilian Education; Youth and Adult Education; teaching modality; Mathematics teaching at EJA; Freirean assumptions and Mathematical Education in the context of Youth and Adult Education, in the perspective of Ethnomathematics bringing the methodologies mobilized for the dissemination of knowledge in this teaching modality and the repercussion of the teaching and learning process linked to the studies of Ethnomathematics. The research revealed that the Freirean assumptions articulated to the studies of Ethnomathematics are present when the teacher creates arguments and surveys socio-cultural and educational problems with students to work on mathematical content. Thus, Freire's studies, those of Ethnomathematics and Mathematical Education present an interlocution in the implementation and organization of the teaching of Mathematics for EJA, with problematization and dialogue as driving elements in the construction of teaching and learning

Keywords: Paulo Freire Method; Mathematica Education; Youth and Adult Education and Ethnomathematics Teaching and Learning.

\section{INTRODUÇÃO}

A Matemática exerce um importante papel em nossas vidas, com ela resolvemos problemas, situações do cotidiano e do mundo do trabalho. O estudante jovem ou adulto, durante sua vida vai acumulando experiências pessoais e construindo vários conhecimentos que são acumulados e levados para a sala de aula. Assim, a prática pedagógica deve ser estruturada para que os conteúdos trabalhados em sala de aula tenham sentido e significado para o estudante.

Na Educação de Jovens e Adultos (EJA), é necessário trabalhar os conteúdos de forma contextualizada com a realidade do estudante para despertar uma maior vontade em aprender, pois, geralmente, esse estudante é um trabalhador, em busca de conhecimentos e qualificações para a progressão profissional e a busca de melhores rendimentos.

Dessa forma, cabe ao professor ter a sensibilidade de elaborar as atividades que estimulam e desperte a curiosidade e o interesse pela Matemática, buscando métodos que tornem a aprendizagem da Matemática prazerosa, mostrar sua aplicação no cotidiano e evidenciar que ela está imersa em nosso meio. Nessa direção a Base Nacional Curricular Comum (BNCC), destaca que:

[...] o conhecimento matemático é necessário para todos os alunos da Educação Básica, seja por sua grande aplicação na sociedade contemporânea, seja pelas suas potencialidades na formação de cidadãos críticos, cientes de suas responsabilidades sociais (BRASIL, 2018, p. 265). 
Ademais e de acordo com os Parâmetros Curriculares Nacionais (PCN), é necessário que o professor "conheça a história de vida dos estudantes, sua vivência de aprendizagens fundamentais, seus conhecimentos informais sobre um dado assunto, suas condições sociológicas, psicológicas e culturais" (BRASIL, 1997, p. 29). Todavia, Freire (2009, p. 16), diz que "ensinar exige respeito aos saberes do educando", assim, tanto o educador quanto a instituição de ensino, precisam "discutir com os estudantes a razão de ser de alguns desses saberes em relação com o ensino dos conteúdos".

A esses contextos de vivência cotidiana dos estudantes, que também emergem suas histórias de vida, seus saberes e fazeres, podem balizar os conhecimentos escolar, ou seja, se faz uma reorientação nas ações docentes por meio de "uma pedagogia na linha da etnomatemática" (D’AMBROSIO, 2002). Refletindo ainda sobre a Etnomatemática e suas possibilidades pedagógicas, temos de acordo com D’Ambrosio (2002, p. 7), que esta Tendência em Educação Matemática procura entender "o fazer e o saber matemático que se desenvolve a partir da dinâmica da evolução de fazeres e saberes que resultam da exposição mútua de culturas". Desse modo, os estudos d'ambrosiano sobre a Etnomatemática demonstram a importância sobre como cada grupo cultural produz a Matemática, para os diferentes fins de sobrevivência.

Nesse sentido, torna-se importante constituirmos diálogos acerca das contribuições de Paulo Freire para os estudos e na perspectiva da Etnomatemática no contexto da Educação de Jovens e Adultos, com o ensino de Matemática, pois os estudantes dessa modalidade são trabalhadores de diferentes segmentos e trazem para a escola vários conhecimentos e experiências do dia a dia.

Para tanto, o conhecimento matemático precisa ser interessante e atrativo, devidamente contextualizado para a realidade dos estudantes, deve estimular a capacidade crítica e a criatividade do educando, respeitando a diversidade cultural, favorecendo a interação, a troca de experiências e saberes dentro de uma mesma turma de estudantes. Na perspectiva do diálogo educativo e constitutivo, passaremos a descrever sobre as contribuições de Paulo Freire para a Educação como um todo. 


\section{PAULO FREIRE E SUA IMPORTÂNCIA PARA EDUCAÇÃO BRASILEIRA}

A história das ideias pedagógicas nesses últimos anos apresenta importantes marcos teóricos, entre os mais significativos podemos citar várias obras de Paulo Freire, que tem servido para fundamento teórico de trabalhos acadêmicos e inspirado diversas áreas do conhecimento, a saber: a Pedagogia, a Matemática, a Filosofia, a Antropologia, a Ecologia, a Medicina, a Psicologia, a História, o Teatro, a Música, a Sociologia, a Letras, a Ciência Política, dentre outros.

Assim será mencionado aqui os dados biobibliográficos de Paulo Freire por considerarmos necessário uma melhor compreensão sobre sua filosofia e metodologia educacional desenvolvida por esse educador no Brasil e no mundo.

Paulo Reglus Neves Freire (1921 - 1997), filho de Joaquim Temístocles Freire e Edeltrudes Neves Freire, foi um brilhante educador brasileiro que discutiu na sua concepção teórica questões importantes, como: Educação, Movimentos Sociais, Educação Popular, Alfabetização de Jovens e Adultos, Libertação e outras temáticas, de modo tal que:

Engajou-se na formação de jovens e adultos trabalhadores. Formou-se em Direito, mas não exerceu a profissão, preferindo dedicar-se a projetos de alfabetização. Nos anos 50, quando ainda se pensava na educação de adultos como uma pura reposição dos conteúdos transmitidos às crianças e jovens, Paulo Freire propunha uma pedagogia específica, associando estudo, experiência vivida, trabalho, pedagogia e política (GADOTTI, 1996, p. 70).

Sua filosofia educacional expressou-se primeiramente em 1958 na sua tese de concurso para a Universidade do Recife, em seguida como professor de Filosofia e História da Educação daquela Universidade, como também em suas primeiras experiências de alfabetização no município de Angicos, Rio Grande do Norte, em 1963.

Paulo Freire com muita coragem pôs em prática um autêntico trabalho de educação que identifica a alfabetização com um processo deconscientização e capacita o oprimido tanto para a aquisição dos instrumentos de leitura e escrita como para sua libertação que fez dele um dos primeiros brasileiros a ser exilado.

No ano de 1969 Freire trabalhou como professor na Universidade de Harvard, com numerosos grupos engajados em novas experiências educacionais tanto em zonas urbanas 
quanto rurais. Durante os 10 anos seguintes, foi Consultor Especial do Departamento de Educação do Conselho Mundial das Igrejas, em Genebra (Suíça) e deu consultoria educacional a vários governos do Terceiro Mundo, principalmente na África.

Em 1980, após 16 anos de exílio, retornou ao Brasil. Lecionou na Universidade Estadual de Campinas (Unicamp) e na Pontifícia Universidade Católica de São Paulo (PUC-SP). No ano de 1989, tornou-se Secretário de Educação no Município de São Paulo. Durante seu mandato, fez um grande esforço na implementação de movimentos de alfabetização, revisão curricular e recuperação salarial dos professores.

No ano de 1997 foi lançado seu último livro: "Pedagogia da Autonomia: saberes necessários à prática educativa" e faleceu no dia 02 de mai o de 1997, em São Paulo.

Paulo Freire foi reconhecido mundialmente pela sua práxis educativa com diversas homenagens e seu nome foi adotado por várias instituições no Brasil e no exterior.

Para Gadotti (1996, p. 79):

O que mais chamou atenção de início foi a fato de que o método Paulo Freire 'acelerava' o processo de alfabetização de adultos. Lauro de Oliveira Lima foi um dos primeiros a observar esse processo. Ele observou a aplicação do método nas cidades-satélites de Brasília e escreveu um relatório onde sustenta que Paulo Freire parte de "estudos de caráter sociológico" e se baseia na "teoria das comunicações". Oliveira Lima percebeu que Paulo Freire não queria aplicar ao adulto analfabeto o mesmo método de alfabetização das crianças. Outros já pensavam assim. Todavia, Paulo Freire foi o primeiro a sitematizar e experimentar um método inteiramente criado para a educação de adultos.

Nessa esteira, para Gadotti (1996, p. 80) pode-se dizer que o "Método Paulo Freire" consiste em três momentos dialética e interdisciplinarmente entrelaçados:

a) a investigação temática, pela qual aluno e professor buscam, no universo vocabular do aluno e da sociedade onde ele vive, as palavras e temas centrais de sua biografia; b) a tematização, pela qual eles codificam e decodificam esses temas; ambos buscam o seu significado social, tomando assim consciência do mundo vivido; e c) a problematização, na qual eles buscam superar uma primeira visão mágica por uma visão crítica, partindo para a transformação do contexto vivido. Dada essa interdisciplinaridade, a obra de Paulo Freire pode ser vista tomando-o seja como cientista, seja como educador. Contudo, essas duas dimensões supõem uma outra: Paulo Freire não as separa da política. Paulo Freire deve ser considerado também como político. Esta é a dimensão mais importante da sua obra. Ele não pensa a realidade como um sociólogo que procura apenas entendê-la. Ele 
busca, nas ciências (sociais e naturais), elementos para, compreendendo mais cientificamente a realidade, poder intervir de forma mais eficaz nela. Por isso ele pensa a educação ao mesmo tempo como ato político, como ato de conhecimento e como ato criador.

No entanto, o pensamento de Paulo Freire tem uma relação direta com a realidade, pois ele comprometeu-se com uma realidade a ser transformada, uma educação para libertação e para transformação a realidade.

Paulo Freire propõe uma nova concepção da relação pedagógica. Não se trata de conceber a educação apenas como transmissão de conteúdos por parte do educador. Pelo contrário, trata-se de estabelecer um diálogo, isso significa que aquele que educa está aprendendo também. A pedagogia tradicional também afirmava isso, só que em Paulo Freire o educador também aprende do educando da mesma maneira que este aprende dele. Não há ninguém que possa ser considerado definitivamente educado ou definitivamente formado. Cada um, a seu modo, junto com os outros, pode aprender e descobrir novas dimensões e possibilidades da realidade na vida. A educação torna-se um processo de formação mútua e permanente (GADOTTI, 1996, p. 80).

Nesse sentido, o diálogo, na prática pedagógica constitui uma negação da pedagogia autoritária, que Paulo Freire chamava de "bancária", ou seja, é o contrário da pedagogia libertadora também proposta por Freire, onde o diálogo é um dos aspectos mais importante desta pedagogia.

Observa-se que o diálogo é um recurso imprescindível na educação e todos têm direito de utilizarem em uma relação de troca de saberes e mútuo respeito.

Em relação ao diálogo, Freire (2009, p. 86), diz:

A formação dos professores e das professoras devia insistir na constituição deste saber necessário e que me faz certo desta coisa óbvia, que é a importância inegável que tem sobre nós o contorno ecológico, social e econômico em que vivemos. E ao saber teórico desta influência teríamos que juntar o saber teórico-prático da realidade concreta em que os professores trabalham. Já sei, não há dúvida, que as condições materiais em que e sob que vivem os educandos Ihes condicionam a compreensão do próprio mundo, sua capacidade de aprender, de responder aos desafios. Preciso, agora, saber ou abrir-me à realidade desses alunos com quem partilho a minha atividade pedagógica. Preciso tornar-me, se não absolutamente íntimo de sua forma de estar sendo, no mínimo, menos estranho e distante dela e a diminuição de minha estranheza ou de minha 
distância da realidade hostil em que vivem meus alunos que não é uma questão de pura geografia.

Desse modo, a relação dialógica sugere um novo estilo de educador e educando e de ensino e aprendizagem, da ação de conhecer e desvendar o mundo, onde o conhecimento não seja estático.

Segundo Freire (2009) uma das importantes buscas para o ensino dos conhecimentos, incluindo os da Matemática, é ouvir a voz dos sujeitos dos grupos estudados, assim, a comprovação dos conhecimentos dos outros e de seu modo de interpretar a realidade.

Nesse sentido, a dialogicidade com os estudantes da Educação de Jovens e Adultos é muito importante para promover o desenvolvimento e o encontro cultural de uma metodologia de ensino, tendo como base os princípios da Etnomatemática, de maneira respeitosa, solidária e comprometida. Com vista a compreendermos a realidade da Educação de Jovens e Adultos, passaremos a descrever considerando de outros marcos teóricos o legais, que fomentam essa modalidade de ensino.

\section{EDUCAÇÃO DE JOVENS E ADULTOS: MODALIDADE DE ENSINO}

A Educação de Jovens e Adultos (EJA) é uma modalidade em nível do Ensino Fundamental e Médio, para jovens e adultos que não tiveram acesso ao conhecimento escolar em idade certa e que visa garantir o direito às pessoas que foram excluídas por atravessamentos distintos, dos bancos escolares ou que não tiveram oportunidade de acessá-los.

Ao que se refere as políticas educacionais para essa modalidade de ensino, há de se destacar os vários documentos legais que asseguram a Educação de Jovens e Adultos como um direito de todos, conforme citado pela Constituição Federal de 1988, no art. 208:

O dever do Estado com a educação será efetivado mediante garantia de: I ensino fundamental, obrigatório e gratuito, assegurada, inclusive, sua oferta gratuita para todos os que a ele não tiveram acesso na idade própria". VII - atendimento ao educando, em todas as etapas da educação básica, por meio de programas suplementares de material didático escolar, transporte, alimentação e assistência à saúde (BRASIL, 1988). 
Nessa direção de marcos legais, temos a Lei n 9.394/96 que, trata da Educação de Jovens e Adultos como uma modalidade de ensino da Educação Básica, de modo a regulamentar sua oferta a todos aqueles que não tiveram acesso ou não concluíram o Ensino Fundamental:

\begin{abstract}
Art. 37. A educação de jovens e adultos será destinada àqueles que não tiveram acesso ou continuidade de estudos nos ensinos fundamental e médio na idade própria e constituirá instrumento para a educação e a aprendizagem ao longo da vida.§ 1 o Os sistemas de ensino assegurarão gratuitamente aos jovens e aos adultos, que não puderam efetuar os estudos na idade regular, oportunidades educacionais apropriadas, consideradas as características do alunado, seus interesses, condições de vida e de trabalho, mediante cursos e exames. $\S 200$ Poder Público viabilizará e estimulará o acesso e a permanência do trabalhador na escola, mediante ações integradas e complementares entre si. § 3 ㅇ A educação de jovens e adultos deverá articular-se, preferencialmente, com a educação profissional, na forma do regulamento. Art. 38. Os sistemas de ensino manterão cursos e exames supletivos, que compreenderão a base nacional comum do currículo, habilitando ao prosseguimento de estudos em caráter regular.§ 1 응 Os exames a que se refere este artigo realizar-se-ão: I - no nível de conclusão do ensino fundamental, para os maiores de quinze anos; II no nível de conclusão do ensino médio, para os maiores de dezoito anos.§ 2 ㅇ Os conhecimentos e habilidades adquiridos pelos educandos por meios informais serão aferidos e reconhecidos mediante exames (BRASIL, 1996).
\end{abstract}

Ademais as Diretrizes Curriculares Nacionais para Educação de Jovens e Adultos como são o Parecer CNE/CEB 11/2000 e a Resolução CNE/CEB 1/2000, destacam que devem ser observadas na oferta a estrutura dos componentes curriculares dessa modalidade de ensino, que estabelece:

Como modalidade destas etapas da Educação Básica, a identidade própria da Educação de Jovens e Adultos considerará as situações, os perfis dos estudantes, as faixas etárias e se pautará pelos princípios de equidade, diferença e proporcionalidade na apropriação e contextualização das diretrizes curriculares nacionais e na proposição de um modelo pedagógico próprio, de modo a assegurar: I - quanto à equidade, a distribuição específica dos componentes curriculares a fim de propiciar um patamar igualitário de formação e restabelecer a igualdade de direitos e de oportunidades face ao direito à educação; II- quanto à diferença, a identificação e o reconhecimento da alteridade própria e inseparável dos jovens e dos adultos em seu processo formativo, da valorização do mérito de cada qual e do desenvolvimento de seus conhecimentos e valores; III quanto à proporcionalidade, a disposição e alocação adequadas dos componentes curriculares face às necessidades próprias da Educação de 
Jovens e Adultos com espaços e tempos nos quais as práticas pedagógicas assegurem aos seus estudantes identidade formativa comum aos demais participantes da escolarização básica (BRASIL, 2000).

Portanto, é por meio desse Parecer que vem à tona a persistência da Educação de Jovens e Adultos (EJA) como promessa de uma via de desenvolvimento para todas as pessoas, para atualização de conhecimentos e habilidades, troca de experiências e acesso a novas regiões de trabalho e da cultura. Trata-se de um compromisso de reparação, qualificação e equalização e de expectativa de vida para todos.

Todavia a Resolução no 3/2010, diz que:

Institui Diretrizes Operacionais para a Educação de Jovens e Adultos nos aspectos relativos à duração dos cursos e idade mínima para ingresso nos cursos de EJA; idade mínima e certificação nos exames de EJA; e Educação de Jovens e Adultos desenvolvida por meio da Educação a Distância (BRASIL, 2010, p. 1).

Nesse sentido a EJA têm por finalidade ajudar o indivíduo a desenvolver suas capacidades, habilidades e potencialidades. Assim, os jovens e adultos que estão retornando aos bancos escolares devem ser vistos como sujeitos sócio-histórico-culturais, com experiências e conhecimentos acumulados, com tempo próprio de formação, contatos cotidianos, saberes e participação, com elaboração entre saberes locais e saberes universais, numa perspectiva de ressignificação da concepção de mundo e de si.

É importante ressaltar que são muitas as vantagens e os elementos de convicção de sucesso da pessoa que busca sua formação, pois acredita que só a partir dela é que é possível a concretização de seu ideário que impulsiona a ação para ser mais e, porque não dizer ter mais.

O estudante da EJA possuí cultura, conhecimentos prévios e sua diversidade de conhecimentos precisam ser aproveitados em sala de aula. Dessa maneira ao compreender a diversidade existente, é necessário que o educador articule um diálogo que respeite essas culturas e conhecimentos. Nessa direção, Freire $(2009$, p. 57) diz que:

É preciso reenfatizar que a multiculturalidade como fenômeno que implica a convivência num mesmo espaço de diferentes culturas não é algo natural e espontâneo. É uma criação histórica que implica decisão, vontade política, mobilização, organização de cada grupo cultural com vistas a fins comuns. 
Que demanda, portanto, certa parte educativa coerente com esses objetivos. Que demanda uma nova ética no respeito às diferenças.

Compreender a EJA como direito refere-se ao direito à vivência plena, à garantia de práticas educativas que vão além da escola, assegurando aos educandos habilidades e competências para que estes sejam capazes de desenvolver plenamente os quatro pilares básicos da aprendizagem: aprender a ser, fazer, conviver e conhecer, independente de classe, gênero, raça e religião. Nesse sentido, acredita-se que a prática pedagógica do educador matemático, imbuída dos princípios da "Educação Libertadora" (FREIRE, 2005, p. 71), certamente irá contribuir para a formação de educandos reflexivos, críticos e consciente de suas ações. Sobre as possiblidades didática e pedagógica do ensino de Matemática junto aos estudantes jovens e adultos, passaremos a refletir.

\section{O ENSINO DA MATEMÁTICA NA EJA}

De modo geral, o ensino da Matemática ainda é um dos grandes desafios a ser enfrentado na Educação, pois as pesquisas mostram que ela é responsável por grande parte da evasão e do fracasso escolar.

Observa-se que isso acontece no ensino de matemática porque muitas vezes o conteúdo não é trabalhado a partir do cotidiano dos alunos e pela falta de uso de metodologias e outros desafios docentes encontrados que pode auxiliar no processo de ensino e de aprendizagem.

Segundo Freitas Filho (2012, p. 29), em relação à prática pedagógica do ensino da Matemática:

A presente proposta do MEC traz uma importante discussão quanto às implicações do ensino de Matemática na Educação de Jovens e Adultos no Brasil, bem como os desafios docentes encontrados. Um dos aspectos discutidos é a escassez de materiais didáticos pedagógicos publicados para atendimento a esse público, o que implica em adequações trazidas do ensino regular feitas por vários professores, obrigando-os a se prenderem às vezes a uma única série. $O$ segundo aspecto evidenciado são as falhas das políticas públicas destinadas á formação de professores, objeto constante de discussões. $O$ terceiro foi a escolha de livros didáticos que não atendem a essa modalidade, inúmeras vezes abordando uma grande quantidade de exercícios mecanizados, divergindo do que é previsto pelos Parâmetros Nacionais de Matemática do ano de 1998 (PCN) que relata que 
o aluno deverá ser estimulado a questionar sua própria resposta, a transformar um dado problema numa fonte de novos problemas. Deste modo, a aprendizagem não se limitará pela reprodução de conhecimentos e sim pela transformação de ações.

O autor fala sobre a falta de recursos humanos e materiais necessários para que o ensino da Matemática realmente seja contemplado de acordo com as orientações presentes na Proposta Curricular para a EJA, publicada pelo Ministério da Educação (MEC) em 2002 (FREITAS FILHO, 2012).

Além disso é necessário que a instituição de ensino esteja atenta às diversas influências, para que sejam propostas atividades que favoreçam o ensino de matemática de modo significativo, visto que:

\begin{abstract}
Nas últimas décadas, em diferentes campos do conhecimento, crescem as investigações sobre os saberes gerados por diferentes grupos culturais referentes à linguagem, aos procedimentos matemáticos (a etnomatemática é um exemplo), às crenças religiosas, aos rituais, às técnicas de produção, à dança, à música etc. No entanto, esses conhecimentos ainda não são tratados como tal e sua presença nos currículos escolares é ainda bastante pequena. Esses conhecimentos também não fazem parte dos livros e textos, em que apenas os chamados saberes "científicos" são veiculados. Mas eles fazem, de fato, parte do mundo dos alunos, particularmente do aluno da EJA. Desse modo, é necessário romper a preconceituosa barreira que separa "saberes populares" de "saberes científicos", pondo em discussão a própria concepção de conhecimento (BRASIL, 2002, p. 103).
\end{abstract}

Para Cembranel (2009, p. 8), “o ensino da matemática está centrado nos procedimentos de cálculo e não sobre os métodos que encorajam a construção espontânea e autônoma dos saberes matemáticos". Assim, a vida cotidiana do educando, principalmente da Educação de Jovens e Adultos, deve ser o ponto de partida das conquistas em sala de aula.

Sobre a Educação para jovens e adultos, não se pode renegar o conhecimento que os educandos trazem, nem esquecer que eles já aprenderam Matemática de forma assistemática.

Os estudantes da EJA têm muitas peculiaridades em vários sentidos, como: as dificuldades de aprendizagem, o tempo de afastamento dos estudos, diferentes faixas etárias, formado por adolescentes, jovens, adultos que estão em busca de melhores 
condições de trabalho e de vida. Com tudo disso, esta modalidade de ensino precisa ter uma atenção especial por parte do poder público, dos educadores, gestores e sociedade em geral.

Para Gadotti (2003, p. 3):

É preciso respeitar o aluno através de uma metodologia apropriada, uma metodologia que resgate a importância da sua biografia. [...] os jovens e adultos alfabetizandos já foram desrespeitados uma vez quando tiveram seu direito à educação negado. Não podem agora, ao retomar sua instrução, serem humilhados mais uma vez por uma metodologia que thes nega o direito de afirmação de sua identidade, de seu saber, de sua cultura.

Desse modo, é importante que os professores busquem metodologias diferenciadas para ensinar de forma que o estudante faça uma relação entre sua realidade social, o cotidiano e o que aprenderam na escola.

Para Vasconcelos (2008, p. 46):

Embora as situações do dia-a-dia tenham grande importância no sentido de favorecer a construção de significados para muitos conteúdos a serem estudados, faz-se necessário considerar a possibilidade de construção de significados a partir de questões internas da própria Matemática, caso contrário, muitos conteúdos seriam descartados por não fazerem parte da realidade dos alunos. Além disso, muitas razões explicam uma formação básica para todas as pessoas e o aspecto utilitário é apenas uma delas.

Segundo as Diretrizes Curriculares Nacionais da Educação Básica, a contextualização é de grande relevância para o processo de aprendizagem:

Um plano de curso elaborado em consonância com o território e o contexto no qual a instituição educacional está inserida e com a realidade do estudante e do mundo do trabalho possibilita, sem dúvida, a realização de aprendizagens que façam sentido para o educando (BRASIL, 2013, p. 245).

Nos PCN consta que é importante estar atento ao trabalhar com situações cotidianas, pois pode haver interpretação ambígua da ideia de contexto ao se dar atenção apenas ao que se supõe ser parte do cotidiano do estudante. 
Ressalta-se que é necessário otimizar a aprendizagem escolar, atrelando-a à vida prática do sujeito. É preciso que o professor esteja familiarizado com o histórico de vida do aluno e condições básicas para a apreensão de conteúdos.

Sabe-se que a Matemática é uma área de conhecimento que proporciona ao estudante entender a realidade a sua volta e agir sobre ela. É essencial no desenvolvimento do pensamento, da criatividade, na formação de capacidades intelectuais, da autonomia e capacidade desses estudantes para enfrentar desafios que lhes são impostos e contribui com a formação deste estudante como cidadão crítico.

Nesse sentido, a contextualização no processo de ensino e de aprendizagem de Matemática diz respeito à vinculação de conhecimento e a situações do cotidiano dos alunos e dos conteúdos da Matemática a outras áreas. Esta prática pedagógica é importante para incentivar e motivar aprendizagem do estudante. Para Fonseca e Alves (2013, p. 9):

[...] há uma visão diferenciada de matemática pelos alunos, dando-lhes a oportunidade de refletirem sobre sua própria prática enquanto estudantes inseridos num meio sociocultural capaz de produzir conhecimento, distorcendo assim, a dura realidade obsoleta da sala de aula.

Santos e Oliveira (2015) ressaltam que, além de considerar a relevância do cotidiano, é necessário criar situações que favoreçam a construção dos significados dos conteúdos matemáticos que serão aprendidos.

Para eles: Contextualizar a Matemática é transformá-la em um instrumento útil à realidade de cada aluno, não no sentido de trabalhar apenas os conteúdos que fazem parte da vida dos educandos, mas de utilizá-los como exemplificações desde que sejam aplicáveis ao contexto (SANTOS; OLIVEIRA, 2015, p. 63).

Com essas discussões nota-se a importância de adequar o trabalho escolar a uma nova realidade, pois a presença da Matemática é marcada em vários campos da atividade humana. Essa adequação a prática escolar certamente irá contribuir de modo mais efetivo para que todos os estudantes tenham acesso a um conhecimento matemático que possibilite realmente a inserção destes educandos na sociedade de forma geral, como cidadãos críticos e atuantes. Nessa perspectiva a Etnomatemática torna-se importante nesse contexto educativo, particularmente, para a ressignificação da prática pedagógica dos 
professores que lecionam matemática na EJA. A esse respeito passaremos a dialogar das bases epistemológicas freiriana e da Educação Matemática no contexto da EJA.

\section{OS PRESSUPOSTOS FREIREANOS E A EDUCAÇÃO MATEMÁTICA NA EDUCAÇÃO DE JOVENS E ADULTOS}

Paulo Freire tornou-se reconhecido internacionalmente pela originalidade do seu pensamento a partir de reflexões situadas em seu tempo e realidade histórico-cultural. Suas obras ampliaram-se numa proposta de educação libertadora, pautada no vínculo pedagógico desenvolvida na Educação.

Para Freire (2005), há um esvaziamento na relação dialética no ensino e aprendizagem quando o educador vê seus educandos como "objetos" para formação, nisso que caracteriza a concepção bancária: A concepção bancária de Educação nega o diálogo, o educador faz depósitos que os educandos recebem pacientemente, memorizam e repetem. "O educador é o que diz a palavra; os educandos, os que a escutam docilmente; o educador é o que disciplina; os educandos, os disciplinados" (FREIRE, 2005, p. 68).

Entende-se que o professor irá "depositar" conhecimentos, vem aí a ideia de "bancária", como se os educandos fossem recipientes a serem preenchidos. Essa educação não é libertadora, mas, sim, opressora, pois não conscientiza os educandos, e sim reforça sua relação vertical e autoritária.

$\mathrm{Na}$ concepção freiriana, a educação libertadora é vista por outra vertente, o estudante é comprometido com a mudança, em busca pela compreensão crítica da realidade que possibilita a libertação dos estudantes de sua condição de opressão, sem imposição, mas com diálogo. Ambos se tornam sujeitos do processo de aprendizagem.

Para compreender sobre os pressupostos de Paulo Freire para o ensino e aprendizagem da Educação de Jovens e Adultos no ensino de Matemática, articulados aos estudos da Etnomatemática, ressalta-se a importância da dialogicidade como expressão da relação entre os professores e os estudantes, de forma solidária, respeitosa e comprometida.

No sentido de dar significado e sentido à realidade do educando e superar a repetição mecânica dos conhecimentos e memorização é importante trabalhar com a problematização que ocorre na relação dialética do ensino e aprendizagem acerca de 
provocações, argumentos e reflexões para novos questionamentos. Assim, a sala de aula transforma-se num diálogo em busca do conhecimento.

Nessa direção, para realizar a leitura de mundo como possibilidade de problematizar a realidade e agir de forma consciente sobre a realidade local dos sujeitos, é necessário que a instituição de ensino valorize a leitura de mundo dos educandos e seus conhecimentos acerca da sua própria realidade com o mundo.

Freire (2009, p. 29) fala sobre a incoerência entre não se realizar uma leitura do mundo e a capacidade de desenvolver um professor crítico, pois segundo ele:

Faz parte de sua tarefa docente não apenas ensinar conteúdos, mas também ensinar a pensar certo. Daí a impossibilidade de vir a tornar-se um professor crítico se, mecanicamente memorizador, é muito mais um repetidor cadenciado de frases e de ideias inertes do que um desafiador.

Para Freire (2009) não há como desenvolver uma visão crítica e produzir conhecimento sem fazer a leitura do vivido, pois a partir da leitura do mundo os educandos são abertos aos diferentes objetos cognoscíveis dentro da realidade que os cerca e atingem novos níveis de percepção ampliando seus conhecimentos.

De acordo com acepção freiriana, a Educação de Jovens e Adultos (EJA) é uma modalidade que atende uma demanda de sujeitos com características específicas, que trazem as marcas de uma exclusão histórica e social e caracterizam as especificidades para essa modalidade.

Sobre o ensino de Matemática nessa modalidade de ensino, ao considerar a trajetória do público a ser atendido, caracteriza-se a Educação Matemática, de acordo com Fonseca (2007, p. 11-12), que a considera:

[...] não como uma modalidade de oferta de Educação Básica ou Profissional, mas como uma ação pedagógica que tem um público específico, definido também por sua faixa etária, mas principalmente por uma identidade delineada por traços de exclusão sociocultural.

Nesse sentido, tendo por base o pensamento pedagógico de Paulo Freire a EJA vislumbra uma educação comprometida com a superação das condições de exclusão e 
opressão, na valorização do meio social dos sujeitos com vistas a alcançar uma mudança real.

Para o ensino de Matemática articulados aos estudos da Etnomatemática, é possível que com o diálogo, problematização, a leitura de mundo e a reflexão, orientem a construção de uma perspectiva educacional na Educação de Jovens e Adultos.

Desse modo, acredita-se que o ensino de Matemática pode ser pensado com base no pensamento de Paulo Freire, de forma a contribuir para reconhecer e valorizar os saberes de vida dos educandos, a partir de elementos colhidos na sua própria realidade e problematizados em meio ao ensino de Matemática. Nesse sentido, passaremos a refletir sobre as potencialidades da Etnomatemática no contexto educativo da EJA.

\section{ETNOMATEMÁTICA NO CONTEXTO DA EDUCAÇÃO DE JOVENS E ADULTOS}

Nos últimos anos várias pesquisas vêm colaborando para temas sobre a perspectiva educacional e cultural na área de Matemática. Dentro do campo da Educação Matemática, alguns estudos mostram que diversos grupos sociais apresentam habilidades próprias de raciocínio, como no que se refere ao uso de calendários, processos de contagem, medidas, sistemas numéricos, entre outros, sendo importante destacar sua utilização em vários aspectos dentro de sua comunidade.

Pode destacar-se que muitos grupos inseridos dentro de nossa sociedade escolarizados ou não, também utilizam conhecimentos empíricos, onde conseguem resolver problemas como se utilizassem o conhecimento matemático, entre outros conhecimentos.

Conforme Santos (2015):

Nesse movimento exponencial, diante destes termos, dos debates, de como interpretar outras lógicas de pensamento de povos culturalmente distintos, no campo da educação matemática, em meados da década de 70 , o professor Ubiratan D’Ambrosio usa a expressão "Etnomatemática". Esta tem o intuito de explicar, conhecer e entender saberes e fazeres de distintos povos. (D'AMBROSIO, 2009, p. 60). Deste modo, a partir da definição de D'Ambrosio (2002, 2004, 2009, 2012), partindo de suas experiências práticas e teóricas, pretende-se esboçar sobre o que o autor citado têm para si em relação ao estudo da Etnomatemática. 
Deste modo, D’Ambrosio (2009) afirma que a Etnomatemática tem o intuito de explicar, entender e conhecer saberes e fazeres de distintos povos e que esses grupos ao produzirem Etnomatemática, saem do sentido escolarizado pensando na perspectiva escolar e oficial, pois, seus conhecimentos utilizados para a produção, validação e construção dos objetos, em grande parte são construídos por necessidades históricas independentes da utilização do pensamento matemático. Assim, não é necessário o conhecimento "oficial" para construir, contar, medir, entre outras atividades pertencentes a sobrevivência.

Segundo D'Ambrosio (2009, p. 60, grifo do autor):

Indivíduos e povos têm, ao longo de suas existências e ao longo da história, criado e desenvolvido instrumentos de reflexão, instrumentos materiais e intelectuais [que chamo ticas] para explicar, entender, conhecer, aprender para saber e fazer [ que chamo de matema] como resposta a necessidades de sobrevivência e de transcendência em diferentes ambientes naturais, sociais e culturais [que chamo de etnos].

Nessa perspectiva, em busca de investigar outros modos de pensamento, inicialmente a Etnomatemática propõe-se entender a partir da história como os povos por meio de instrumentos intelectuais e materiais produziram e continuam produzindo conhecimento para responder a necessidade de sua sobrevivência.

Assim, D’Ambrosio (2012, p. 17 apud SANTOS, 2015) diz que:

A Etnomatemática busca entender ao longo da história da humanidade o saber/fazer. O ser humano, independente de sua cultura tem necessidades básicas no intuito de sua sobrevivência, havendo a necessidade de produção de objetos e técnicas, onde se pode conhecer como seu próprio matema, que se traduz quando os membros da sociedade "compartilham maneiras de explicação, artes e técnicas próprias e especificas" para realizar suas atividades.

Dessa maneira, se com os sistemas lógicos de pensamento, os grupos sociais são capazes de produzirem objetos manipuláveis, criar e modificar suas produções, de acordo com sua necessidade histórica. D’Ambrósio compreende esse processo cumulativo como “[...] estágios de geração, organização intelectual, organização social e difusão do conhecimento" (D'AMBROSIO, 2002, p. 25).

Verifica-se que esses estágios de acordo com o autor são responsáveis pelo processo de uma reprodução de conhecimentos possíveis para manter em constante 
movimento outros sujeitos futuramente. Deste modo, convém ressaltar que o autor denomina que o Programa Etnomatemática,

Teve sua origem na busca de entender o fazer e o saber matemático de culturas marginalizadas. Intrínseco a ele há uma proposta historiográfica que remete à dinâmica da evolução de fazeres e saberes que resultam da exposição mútua de culturas. Em todos os tempos, a cultura do conquistador e do colonizador evolui a partir da dinâmica do encontro. $\mathrm{O}$ Programa Etnomatemática não se esgota no entender o conhecimento [saber e fazer] matemático das culturas periféricas. Procura entender 0 ciclo da geração, organização intelectual, organização social e difusão desse conhecimento. Naturalmente, no encontro de culturas há uma importante dinâmica de adaptação e reformulação acompanhando todo esse ciclo, inclusive a dinâmica cultural de encontros [de indivíduos e de grupos] (D'AMBROSIO, 2002, p. 12-13).

Desta forma, percebe-se a importância de observar os conhecimentos etnomatemáticos, permeados por construções patriarcais e uma visão transcultural com a perspectiva de intermediar convivências em outras culturas, como também, preservar os saberes etnomatemáticos de distintos grupos sociais

D’Ambrósio (2002, p. 15) garante que "a disciplina denominada Matemática é, na verdade, uma Etnomatemática", ou seja, a matemática é vista na Etnomatemática, oriunda de interconexões entra as diferentes culturas.

Nessa esteira, ao ensinar e aprender Matemática na EJA os estudantes têm uma Matemática que advém do seu mundo social e cultural que é fruto de diversas circunstâncias vivenciadas por eles, assim, é necessário repensar a proposta pedagógica a partir da cultura dos educandos, como: trabalhar com resolução de problemas de forma contextualizada com a realidade do educando, dialogicidade entre os sujeitos e leitura de mundo ao propor trabalhos voltados à construção mental nas diversas situações do dia a dia, evidenciando dessa maneira a articulação entre os pressupostos de Paulo Freire e os estudos da Etnomatemática.

Entendidos pela leitura de mundo, dialogicidade, conscientização, problematização e ação-reflexão-ação, articulados aos estudos da Etnomatemática é importante que os conteúdos no ensino da matemática na EJA, sejam trabalhados de forma contextualizada, discutindo-os e relacionando-os a situações que façam sentido para o educando. 
Nessa direção, Ferreira (apud CHIEUS JUNIOR, 2006, p. 185) relata que: “[...] se me perguntarem o que é Etnomatemática eu diria - É matemática, é criança brincando, é pedreiro construindo casa, é dona de casa cozinhando, é índio caçando ou fazendo artesanato, isto é, é parte da vida, da existência de cada um."

Nesse contexto, para atingir os objetivos de integrar os saberes matemáticos na Educação de Jovens e Adultos, a Etnomatemática se apresenta de forma a possibilitar o desenvolvimento de uma aprendizagem significativa, pois procura analisar, revitalizar e valorizar o saber e o fazer matemático produzido em diferentes contextos culturais. Assim, para D’Ambrósio (2008, p. 3):

A etnomatemática propõe uma pedagogia viva, dinâmica, de fazer o novo em resposta a necessidades ambientais, sociais, culturais, dando espaço para a imaginação e para a criatividade. É por isso que na pedagogia da etnomatemática, utiliza-se muito a observação, a literatura, a leitura de periódicos e diários, os jogos, o cinema, etc. Tudo isso, que faz parte do cotidiano, tem importantes componentes matemáticos.

Nessa perspectiva o ensino de Matemática precisa ser interessante, atrativo e contextualizado para não acarretar medo, por causa das exigências de precisão e rigor, que se exige em determinados campos de ensino da Matemática. Deve ser prazeroso e estimular a capacidade crítica e criatividade do estudante. Assim, o ensino da Matemática sob ótica da Etnomatemática e Educação de Jovens e Adultos deve envolver conhecimentos que os estudantes adquiriram nas práticas do dia a dia e oportunizar a capacidade de se inserir de forma ativa no processo de ensino aprendizagem, criando momentos de participação em sala e rompendo com o paradigma da educação "bancária".

\section{CONSIDERAÇÕES FINAIS}

Considerando as concepções do ensino de Matemática na Educação de Jovens e Adultos, surge como uma alternativa para mudar e discutir a importância de valorizar o aspecto histórico e socioculturais do estudante, dinamizando o ensino de Matemática em sala de aula. 
Desse modo, é possível entender a importância de se propor aos estudantes uma Matemática relacionada com suas vivências, experiências capazes de despertar mais interesse e envolvimento, pois pode ser utilizada imediatamente no seu dia a dia.

Nesse contexto, temos que o ensino da Matemática na Educação de Jovens e Adultos, inserido na perspectiva da Etnomatemática, irá trazer possibilidades de mudanças na prática docente do professor, conectando o conhecimento produzido em situações concretas da vida dos estudantes com a prática pedagógica escolar.

A partir desse ponto de vista no qual o processo escolar apresenta real significância, haverá mais qualidade no ensino, uma vez que o professor e o estudante trabalham juntos na construção e aquisição do conhecimento. Dessa maneira, o estudante não será somente um receptor de conteúdos, e sim o elemento central no processo de ensino e de aprendizagem. O professor deixa de ser o transmissor de conteúdos e passa a ser o mediador e o socializador do processo significativo na Educação.

\section{REFERÊNCIAS}

BRASIL, Secretaria de Educação Fundamental. Parâmetros curriculares nacionais: matemática. Brasília: Ministério da Educação e Cultura/Secretaria de Ensino Fundamental, 1998.

BRASIL. Base nacional comum curricular. Brasília: Mec, 2018. Disponível em: http://basenacionalcomum.mec.gov.br/images/BNCC EI EF_110518 versaofinal_site.pdf. Acesso em: 01 jul. 2020.

BRASIL. Constituição da República Federativa do Brasil: promulgada em 5 de outubro de 1988. Disponível em: http://www.planalto.gov.br/ccivil 03/constituicao/constituicao.htm Acesso em: 25 jun 2020.

BRASIL. Lei no 9.394, de 20 de dezembro de 1996. Estabelece as diretrizes e bases da educação nacional. Brasília, DF, 20 dez. 1996. Disponível em: http://www.planalto.gov.br/ccivil_03/Leis/L9394.htm. Acesso em: 25 jun 2020.

BRASIL. Ministério da Educação. Conselho Nacional de Educação. Parecer CNE/CEB 11/2000, de 10 de julho de 2000. Brasília, DF, 10 maio 2000. Disponível em: http://confinteabrasilmais6.mec.gov.br/images/documentos/parecer CNE CEB 11 2000.p df. Acesso em: 01 jul. 2020.

BRASIL. Ministério da Educação. Conselho Nacional de Educação. Resolução CNE/CEB no 1, de 5 de julho de 2000. Estabelece as Diretrizes Curriculares Nacionais para a Educação e 
Jovens e Adultos. Brasília, DF, 5 jul. 2000. Disponível em: http://portal.mec.gov.br/cne/arquivos/pdf/CEB012000.pdf. Acesso em: 13 jul. 2020.

BRASIL. Parâmetros Curriculares Nacionais (PCN). Matemática. Ensino Fundamental. Brasília: MEC/SEF, 1997.

BRASIL. Proposta curricular para a educação de jovens e adultos: segundo segmento do ensino fundamental: $5^{\mathrm{a}}$ a $8^{\mathrm{a}}$ série. Brasília (DF): Ministério da Educação, 2002.

BRASIL.Ministério da Educação. Conselho Nacional de Educação. Resolução no 3, de 15 de junho de 2010. Institui Diretrizes Operacionais para a Educação de Jovens e Adultos nos aspectos relativos à duração dos cursos e idade mínima para ingresso nos cursos de EJA; idade mínima e certificação nos exames de EJA; e Educação de Jovens e Adultos desenvolvida por meio da Educação a Distância. Brasília, DF, 15 jun. 2010. Disponível em: http://confinteabrasilmais6.mec.gov.br/images/documentos/resolucao032010cne.pdf.

Acesso em: 01 jul. 2020.

CEMBRANEL, S. M. O ensino e a aprendizagem de matemática na EJA. 2009. 14f. Trabalho de Conclusão (Especialização) - Universidade Federal do Rio Grande do Sul, Porto Alegre, 2009. Disponível em https://bento.ifrs.edu.br/site/midias/arquivos/20105112711984simone meireles cembrane I.p.Acesso em: 08 set. 2020.

CHIEUS JUNIOR. G. Etnomatemática: reflexões sobre a prática docente. In: RIBEIRO, J. P. M.; DOMITE, M. do C. S.; FERREIRA, R. Etnomatemática: papel valor e significado. 2.ed. Porto Alegre, RS: Zouk, 2006.

D'AMBRÓSIO, Ubiratan. Etnomatemática e Educação. Reflexão e Ação, Santa Cruz do Sul, v. 10, n. 1, p. 7-19, jan./jun. 2002.

D'AMBROSIO, Ubiratan. O programa etnomatemática: uma síntese. Acta Scientiae, Canoas, v. 10, n.1, p7-16, jan./jun. 2008.

D'AMBROSIO, Ubiratan. Etnomatemática: elo entre as tradições e a modernidade. 3. ed. Belo Horizonte: Editora Autêntica, 2009.

D’AMBROSIO, Ubiratan. Transdiciplinaridade. 2. ed. São Paulo: Palas Atenas, 2012.

FONSECA, Adriano; ALVES, Welington Domingos. Etnomatemática e releitura do cotiano: um projeto interdisciplinar em sala de aula. 2013. Disponível em:

http://sbem.iuri0094.hospedagemdesites.ws/anais/XIENEM/pdf/2742_1243 ID.pdf. Acesso em: 10 set. 2020.

FONSECA, M.C.F.R. Educação matemática de jovens e adultos: especificidades, desafios e contribuições. Belo Horizonte: Autêntica, 2007.

FREIRE, Paulo. Pedagogia do oprimido. 43. ed. Rio de Janeiro: Editora Paz e Terra, 2005. 
FREIRE, Paulo. Pedagogia da autonomia: saberes necessários à prática educativa. 39. ed. São Paulo: Paz e Terra, 2009.

FREITAS FILHO, Lourival Alves. Estratégias usadas pelos alunos da educação de jovens $e$ adultos na resolução de problemas aritméticos. 2012. 142 f. Dissertação (Mestrado em Ensino de Ciências e Matemática) - Pontifícia Universidade Católica de Minas Gerais, Belo Horizonte, 2012.

GADOTTI, Moacir (org.). Paulo Freire: uma biobliografia. São Paulo: Cortez, 1996.

GADOTTI, M. A gestão democrática na escola para jovens e adultos: ideias para tornar a escola pública uma escola de EJA. 2003. Disponível em: https://repositorio.usp.br/item/001528596. Acesso em: 8 set. 2003.

SANTOS, A. O.; OLIVEIRA, G. S. de. Contextualização no ensino-aprendizagem da Matemática: princípios e práticas. Educação em Rede: formação e prática docente, Cachoeirinha/RS, v. 4, n. 5, p. 59-75, 2015.

SANTOS, Jonatha Daniel dos. Etnomatemática na perspectiva de Ubirantan D'Ambrosio. 2015. Disponível em: https://www.partes.com.br/2015/12/27/etnomatematica-naperspectiva-de-ubirantan-dambrosio/. Acesso em: 11 set. 2020.

VASCONCELOS, M. B. F. A contextualização e o ensino de matemática: um estudo de caso. 2008. 113 f. Dissertação (Mestrado em Educação) - Universidade Federal da Paraíba, João Pessoa, PB, 2008.

Recebido em 08 de dezembro de 2020.

Aprovado em 31 maio de 2021.

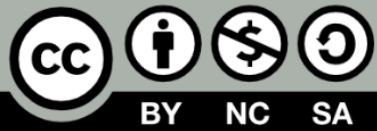

